Article

\title{
Social Inequalities in Prenatal Folic Acid Supplementation: Results from the ELFE Cohort
}

\author{
Aurore Camier 1,2, Manik Kadawathagedara ${ }^{1,2}$, Sandrine Lioret ${ }^{1,2}$, Corinne Bois ${ }^{3}$, \\ Marie Cheminat ${ }^{3}$, Marie-Noëlle Dufourg ${ }^{3}$, Marie Aline Charles 1,2,3 and \\ Blandine de Lauzon-Guillain 1,2,4,*(D)
}

1 INSERM, UMR1153 Center for Research in Epidemiology and StatisticS (CRESS), Research Team on Early Life Origins of Health (EAROH), 75004 Paris, France; aurore.camier@inserm.fr (A.C.); manik.kadawathagedara@inserm.fr (M.K.); sandrine.lioret@inserm.fr (S.L.); marie-aline.charles@inserm.fr (M.A.C.)

2 Université de Paris, UMR1153 Center for Research in Epidemiology and StatisticS (CRESS), Research Team on Early Life Origins of Health (EAROH), 75004 Paris, France

3 Unité Mixte Inserm-Ined-EFS Elfe, Ined, 75020 Paris, France; corinne.bois@ined.fr (C.B.); marie.cheminat@ined.fr (M.C.); marie-noelle.dufourg@ined.fr (M.-N.D.)

4 INRA, U1125 Center for Research in Epidemiology and StatisticS (CRESS), Research Team on Early Life Origins of Health (EAROH), 75004 Paris, France

* Correspondence: blandine.delauzon@inserm.fr; Tel.: +33-145-595-019; Fax: +33-147-269-454

Received: 23 April 2019; Accepted: 15 May 2019; Published: 18 May 2019

\begin{abstract}
Most professional and international organizations recommend folic acid supplementation for women planning pregnancy. Various studies have shown high levels of non-compliance with this recommendation. This study aimed to identify sociodemographic characteristics related to this compliance. The analyses were based on 16,809 women from the French nationwide ELFE cohort (Etude Longitudinale Française depuis l'Enfance). Folic acid supplementation was assessed at delivery, and sociodemographic characteristics were collected at two months postpartum. The association between sociodemographic characteristics and compliance with recommendations on folic acid supplementation (no supplementation, periconceptional supplementation, and supplementation only after the periconceptional period) was examined using multivariate multinomial logistic regression. Only $26 \%$ of French women received folic acid supplementation during the periconceptional period, $10 \%$ of women received supplementation after the periconceptional period, and $64 \%$ received no supplementation. Young maternal age, low education level, low family income, multiparity, single parenthood, maternal unemployment, maternal overweight, and smoking during pregnancy were related to lower likelihood of folic acid supplementation during the periconceptional period compared to no supplementation. These associations were not explained by unplanned pregnancy. Immigrant and underweight women were more likely to receive folic acid supplementation after the periconceptional period. Our study confirms great social disparities in France regarding the compliance with the recommendations on folic acid supplementation.
\end{abstract}

Keywords: folic acid supplementation; pregnancy; epidemiology; social inequalities

\section{Introduction}

Neural tube defects are one of the most common congenital diseases in Europe [1] and, in France, represent 1.3 cases (live births, fetal deaths, termination of pregnancy for fetal anomaly) per 1000 births [2]. Randomized trials have proved the efficacy of folic acid supplementation during the periconceptional period in neural tube defects prevention [3-5]. 
Most professional and international organizations, including the World Health Organization, recommend folic acid supplementation for women planning pregnancy [6,7]. However, the specifically targeted population groups (e.g., women of childbearing age, women planning pregnancy, women of childbearing age without safe contraception) and the timing or duration of the supplementation recommendations vary across countries. In North America, maternal folic acid intake is addressed by the folic acid fortification of food products (flours, cereals) [8], whereas, in Europe, the prevention policy is based on supplementation exclusively. In France, the latest guidelines from the Agency for Food, Environmental, and Occupational Health \& Safety reinforced the need for folic acid supplementation for women within the periconceptional period (eight weeks before and eight weeks after conception) to achieve a daily intake of $400 \mu \mathrm{g}$ dietary folate equivalents [9].

The neural tube defects prevention policy based on folic acid supplementation during the periconceptional period assumes that pregnancies are planned and that future mothers visit health professionals before pregnancy. However, in Europe, 45\% of pregnancies were unintended in 2012 [10], and women from disadvantaged households tend to have lower access to health services, particularly for preventive care [11-13].

Within this context, the objective of the present study was to identify sociodemographic characteristics associated with compliance with recommendations on folic acid supplementation to prevent neural tube defects in France, with a special focus on the timing of this supplementation, on the basis of a national survey performed in 2011 on women giving birth.

\section{Materials and Methods}

\subsection{Study Population}

The present study was based on the ELFE study (Etude Longitudinale Française depuis l'Enfance), a multidisciplinary study comprising a nationally representative birth cohort, which included 18,258 children born in 349 randomly selected maternity units in France in 2011 [14]. Inclusion took place during 25 selected recruitment days over 4 waves encompassing 4 to 8 days each and all 4 seasons. Inclusion criteria were as follows: children born after 33 weeks of gestation, mothers aged 18 years or older and who were not planning to move outside of metropolitan France during the following three years. Foreign families could also participate in the study if mothers were able to read French, Arabic, Turkish, or English. Participating mothers signed informed consent for themselves and their child. A total of $51 \%$ of contacted parents agreed to participate. Data were collected through standardized interviews conducted by trained midwives and through self-completed questionnaires. The follow-up of this birth cohort is ongoing.

The ELFE study was given ethical approval by the Advisory Committee for the Treatment of Information on Health Research (Comité Consultatif sur le Traitement des Informations pour la Recherche en Santé), the National Agency Regulating Data Protection (Commission National Informatique et Libertés), and the National Statistics Council.

\subsection{Maternal Characteristics}

Mothers were first interviewed in the maternity ward after delivery, to collect information about their pregnancy, their newborn, and their general characteristics (employment status, education level, age). Two months post-partum, telephone interviews with mothers and fathers took place, which included additional questions on demographic and socioeconomic characteristics such as country of birth, educational level, employment, monthly income, and number of family members.

As family data were more comprehensively collected during the two-month-post-partum interview than during the maternity interview and because family sociodemographic characteristics only marginally evolved within two months, we prioritized data collected at two months in our analyses. The sociodemographic characteristics collected during the maternity stay were used only in the case of missing values in the two-months-post-partuminterview. Maternal characteristics included in 
the analyses were: migration status (native French, immigrant, descendant of immigrants), age at first delivery (18-25 years, 25-29 years, 30-34 years, $\geq 35$ years), family type (traditional, stepfamily, one-parent family), educational level measured on the basis of the highest academic degree attained (<secondary school, secondary school, high school, two-year university degree, $\geq$ three-year university degree), employment status (employed, housewife/parental leave, retired/disability/unemployed, student, other), monthly family income ( $\leq € 1500$, €1501-2300, €2301-3000, €3001-4000, €4001-5000, $>€ 5000$ ), smoking status (never smoked, smoked only before pregnancy, smoked until early pregnancy, smoked during the whole pregnancy), planned pregnancy, and fertility treatment.

\subsection{Folic Acid Supplementation}

Information on maternal folic acid supplementation was collected retrospectively at the maternity unit during face-to-face interviews utilizing five questions: 'Have you taken folic acid (also called vitamin B9) before and/or during pregnancy (to prevent nervous system abnormalities)?' 'If yes, indicate the periods of time you took it: one to three months before pregnancy (yes/no), in the first two months of pregnancy (yes/no), between the second and sixth month of pregnancy (yes/no), beyond six months of pregnancy (yes/no)'. Women were divided into three groups according to their folic acid supplementation: supplementation during the periconceptional period (before pregnancy and/or first two months of pregnancy), late supplementation (only after the second month of pregnancy), and no supplementation. No information about family history of neural tube defects or folic acid supplements dosages was collected.

\subsection{Sample Selection}

Women who withdrew consent within the first year $(n=128)$ or for whom it was not possible to verify the eligibility criteria due to missing data $(n=350)$ were excluded from the study, resulting in 17,574 eligible mothers. We also excluded women with missing data $(n=3418)$, leaving a total of 14,156 women in the main analyses.

\subsection{Statistical Analyses}

Comparisons between excluded and included subjects were conducted with chi-square tests.

In order to provide representative descriptive statistics of births in 2011 in France, the descriptive data (rates) were weighted to consider the sampling design and biases related to non-consent. Weighting also included calibration on margins from the state register of statistical data and the 2010 French National Perinatal study [15] regarding the following variables: age, region, marital status, migration status, level of education, and primiparity.

Associations between sociodemographic variables and folic acid supplementation were tested by multivariable multinomial logistic regression, including maternal characteristics (maternal age at first delivery, parity, family composition, migration status, education level, employment status, family income, pre pregnancy body mass index (BMI), smoking status), and additionally adjusted for mothers' region of residence, size of maternity unit, and wave of recruitment.

Several sensitivity analyses were performed. First, analyses were performed only for women with planned pregnancy and without fertility treatment, in order to check that the associations between familial characteristics and compliance with folic acid supplementation guidelines were not driven by the specific cases of unplanned pregnancy or fertility treatment. Then, we calculated weighted multivariate models. Afterward, using multiple imputations to deal with missing data on sociodemographic variables, using the SAS software. We assumed that data were missing at random and generated five independent datasets using the fully conditional specification method (MI procedure, FCS statement, NIMPUTE option) and then calculated pooled effect estimates (MIANALYSE procedure). Imputation model variables included both the potentially predicting non-response and the outcomes. Categorical variables were imputed using a multinomial model, ordinal or binary variables using 
logistic regressions, and continuous variables using linear regressions. Further details are available in Supplementary Table S1.

\section{Results}

Women excluded from our analysis were younger, more likely to be single, born in a country other than France, had a lower education level, were less likely to be employed during pregnancy, and had quit smoking before pregnancy compared to women included in our analysis (Table 1).

Table 1. Study sample characteristics.

\begin{tabular}{|c|c|c|c|}
\hline & Excluded Women & Included Women & $p$-Value \\
\hline $\mathrm{N}$ & 3418 & 14,156 & \\
\hline Age at delivery (years) & $29.4(5.7)$ & $30.4(4.9)$ & $<0.0001$ \\
\hline Birth order & & & $<0.0001$ \\
\hline First child & $43.7 \%(1491)$ & $45.0 \%(6365)$ & \\
\hline Second child & $33.5 \%(1142)$ & $36.0 \%(5101)$ & \\
\hline Third child & $14.3 \%(488)$ & $13.8 \%(1949)$ & \\
\hline Fourth child or more & $8.5 \%(291)$ & $5.2 \%(741)$ & \\
\hline Single parenthood & & & $<0.0001$ \\
\hline Yes & $12.4 \%(414)$ & $3.9 \%(548)$ & \\
\hline No & $87.6 \%(2928)$ & $96.1 \%(13,549)$ & \\
\hline Country of birth & & & $<0.0001$ \\
\hline France & $78.5 \%(2599)$ & $88.9 \%(12,516)$ & \\
\hline Another country & $21.5 \%(713)$ & $11.1 \%(1568)$ & \\
\hline Education level & & & $<0.0001$ \\
\hline Primary school & $11.2 \%(376)$ & $3.5 \%(491)$ & \\
\hline Secondary school & $20.0 \%(673)$ & $12.6 \%(1783)$ & \\
\hline General high school & $11.2 \%(378)$ & $7.2 \%(1023)$ & \\
\hline Technical/professional high school & $15.7 \%(530)$ & $12.3 \%(1741)$ & \\
\hline University & $41.9 \%(1410)$ & $64.4 \%(9116)$ & \\
\hline Employment status & & & $<0.0001$ \\
\hline Employed & $59.3 \%(1968)$ & $72.7 \%(10,298)$ & \\
\hline Housewife/parental leave & $2.5 \%(83)$ & $3.4 \%(485)$ & \\
\hline Retired/disability/unemployed & $11.9 \%(395)$ & $12.0 \%(1702)$ & \\
\hline Student & $21.7 \%(721)$ & $10.1 \%(1424)$ & \\
\hline Other & $4.6 \%(154)$ & $1.7 \%(247)$ & \\
\hline Pre-pregnancy body mass index $\left(\mathrm{kg} / \mathrm{m}^{2}\right)$ & $23.7(5.1)$ & $23.4(4.7)$ & 0.0138 \\
\hline Smoking status & & & $<0.0001$ \\
\hline Never smoked & $59.0 \%(1902)$ & $56.7 \%(8020)$ & \\
\hline Smoked only before pregnancy & $18.1 \%(585)$ & $23.7 \%(3356)$ & \\
\hline Smoked only during early pregnancy & $4.0 \%(130)$ & $3.9 \%(559)$ & \\
\hline Smoker during the whole pregnancy & $18.9 \%(608)$ & $15.7 \%(2221)$ & \\
\hline
\end{tabular}

Values are $\%(n)$.

The weighted rate of folic acid supplementation was $26.0 \%$ during the periconceptional period and $9.9 \%$ for supplementation started only after the first two months of pregnancy. A total of $64.1 \%$ of women did not receive folic acid supplementation before or during pregnancy.

Bivariable associations between maternal characteristics and folic acid supplementation are shown in Table 2. 
Table 2. Bivariate analyses between familial characteristics and folic acid supplementation.

\begin{tabular}{|c|c|c|c|c|c|}
\hline & $N$ & $\begin{array}{c}\text { No } \\
\text { Supplementation } \\
(N=8328)\end{array}$ & $\begin{array}{l}\text { Periconceptional } \\
\text { Supplementation } \\
\qquad(N=4520)\end{array}$ & $\begin{array}{c}\text { Late } \\
\text { Supplementation } \\
\text { Only }(N=1308)\end{array}$ & $p$-Value \\
\hline Age at first delivery & & & & & $<0.0001$ \\
\hline$<25$ years & 3611 & $74.9 \%$ & $15.1 \%$ & $9.6 \%$ & \\
\hline 25-29 years & 6134 & $59.9 \%$ & $31.3 \%$ & $8.7 \%$ & \\
\hline 30-34 years & 3412 & $50.7 \%$ & $38.7 \%$ & $9.8 \%$ & \\
\hline$\geq 35$ years & 999 & $49.9 \%$ & $39.3 \%$ & $9.6 \%$ & \\
\hline Parity & & & & & $<0.0001$ \\
\hline First child & 6365 & $55.2 \%$ & $35.4 \%$ & $9.0 \%$ & \\
\hline Second child & 5101 & $63.4 \%$ & $26.9 \%$ & $9.3 \%$ & \\
\hline Third child & 1949 & $67.9 \%$ & $21.8 \%$ & $9.7 \%$ & \\
\hline Fourth child or more & 741 & $78.4 \%$ & $10.9 \%$ & $10.1 \%$ & \\
\hline Family composition & & & & & $<0.0001$ \\
\hline Traditional & 12,499 & $59.7 \%$ & $30.6 \%$ & $9.2 \%$ & \\
\hline Single parenthood & 532 & $80.7 \%$ & $11.1 \%$ & $8.8 \%$ & \\
\hline Stepfamily & 1125 & $68.8 \%$ & $20.9 \%$ & $10.3 \%$ & \\
\hline Migration & & & & & $<0.0001$ \\
\hline Native French & 10,229 & $60.9 \%$ & $30.1 \%$ & $8.7 \%$ & \\
\hline First-generation immigrant & 1582 & $64.0 \%$ & $23.5 \%$ & $11.7 \%$ & \\
\hline Second-generation immigrant & 2345 & $61.7 \%$ & $27.9 \%$ & $9.7 \%$ & \\
\hline Educational level & & & & & $<0.0001$ \\
\hline$<$ Secondary school & 999 & $76.9 \%$ & $11.8 \%$ & $10.1 \%$ & \\
\hline Secondary school & 2010 & $75.3 \%$ & $16.3 \%$ & $8.9 \%$ & \\
\hline High school & 2620 & $66.4 \%$ & $23.9 \%$ & $8.9 \%$ & \\
\hline Two-year university degree & 3199 & $58.6 \%$ & $31.8 \%$ & $9.5 \%$ & \\
\hline Three-year university degree & 2495 & $52.3 \%$ & $37.8 \%$ & $9.4 \%$ & \\
\hline$\geq$ Five-year university degree & 2833 & $46.5 \%$ & $43.4 \%$ & $9.0 \%$ & \\
\hline Employment status & & & & & $<0.0001$ \\
\hline Employed & 10,298 & $57.0 \%$ & $33.7 \%$ & $9.0 \%$ & \\
\hline Student & 485 & $61.8 \%$ & $30.4 \%$ & $8.7 \%$ & \\
\hline Unemployed & 1702 & $68.5 \%$ & $20.6 \%$ & $11.2 \%$ & \\
\hline Housewife/parental leave & 1424 & $74.6 \%$ & $13.9 \%$ & $9.6 \%$ & \\
\hline Other & 247 & $71.8 \%$ & $21.9 \%$ & $6.9 \%$ & \\
\hline Family income & & & & & $<0.0001$ \\
\hline$<€ 1500 /$ month & 1417 & $78.4 \%$ & $12.3 \%$ & $9.2 \%$ & \\
\hline$€ 1501-2300 /$ month & 2177 & $69.3 \%$ & $19.5 \%$ & $10.5 \%$ & \\
\hline$€ 2301-3000 /$ month & 3974 & $61.4 \%$ & $29.3 \%$ & $9.1 \%$ & \\
\hline$€ 3001-4000 /$ month & 3745 & $56.6 \%$ & $33.8 \%$ & $9.2 \%$ & \\
\hline$€ 4001-5000 /$ month & 1551 & $50.0 \%$ & $40.1 \%$ & $9.1 \%$ & \\
\hline$>€ 5000 /$ month & 1292 & $45.5 \%$ & $45.9 \%$ & $8.0 \%$ & \\
\hline Smoking status & & & & & $<0.0001$ \\
\hline Never smoked & 8020 & $59.7 \%$ & $30.5 \%$ & $9.3 \%$ & \\
\hline Smoked only before pregnancy & 3356 & $56.7 \%$ & $33.7 \%$ & $9.0 \%$ & \\
\hline Smoked only during early pregnancy & 559 & $68.8 \%$ & $21.6 \%$ & $10.7 \%$ & \\
\hline Smoked during the whole pregnancy & 2221 & $72.2 \%$ & $18.3 \%$ & $9.1 \%$ & \\
\hline Planned pregnancy & & & & & $<0.0001$ \\
\hline No & 1203 & $74.6 \%$ & $15.3 \%$ & $10.1 \%$ & \\
\hline Yes & 12,079 & $58.8 \%$ & $31.6 \%$ & $9.0 \%$ & \\
\hline Previous treatment for infertility & & & & & $<0.0001$ \\
\hline No & 12,915 & $63.0 \%$ & $27.2 \%$ & $9.4 \%$ & \\
\hline Yes & 1105 & $42.4 \%$ & $49.6 \%$ & $7.4 \%$ & \\
\hline
\end{tabular}

Values are $n$ and weighted \%. Chi-square tests on weighted data.

Women were less likely to take folic acid supplementation during the periconceptional period, compared to no pre-conceptional supplementation, when they were younger, multiparous, single, with low education level, low family income, unemployed during pregnancy, and smoked during pregnancy (Table 3). Compared to mothers who had never smoked, women who had quit smoking before pregnancy were more likely to take folic acid supplementation during the periconceptional period, whereas the relationship was inverse for those women who smoked during the whole pregnancy. 
Table 3. Multivariate associations between sociodemographic characteristics and timing of folic acid supplementation $(n=14,156)$.

\begin{tabular}{|c|c|c|c|}
\hline & \multicolumn{2}{|c|}{$\begin{array}{c}\text { Folic Acid Supplementation } \\
\text { (Reference = No Supplementation) }\end{array}$} & \multirow[b]{2}{*}{$p$-Value } \\
\hline & $\begin{array}{l}\text { Periconceptional } \\
\text { Supplementation }\end{array}$ & Late Supplementation Only & \\
\hline Age at first delivery & & & $<0.0001$ \\
\hline$<25$ years & $0.72[0.64-0.81]$ & $1.04[0.88-1.23]$ & \\
\hline $25-29$ years & $1[$ Ref $]$ & $1[$ Ref $]$ & \\
\hline 30-34 years & $1.23[1.12-1.36]$ & $1.32[1.13-1.54]$ & \\
\hline$\geq 35$ years & $1.30[1.12-1.51]$ & $1.33[1.04-1.71]$ & \\
\hline Birth order & & & $<0.0001$ \\
\hline First child & 1 [Ref] & 1 [Ref] & \\
\hline Second child & $0.62[0.57-0.68]$ & $0.92[0.80-1.05]$ & \\
\hline Third child & $0.58[0.51-0.66]$ & $0.96[0.80-1.17]$ & \\
\hline Fourth child or more & $0.40[0.32-0.51]$ & $0.87[0.66-1.16]$ & \\
\hline Family composition & & & $<0.0001$ \\
\hline Traditional & 1 [Ref] & $1[$ Ref] & \\
\hline Single-parenthood & $0.73[0.56-0.96]$ & $0.80[0.57-1.12]$ & \\
\hline Stepfamily & $1.22[1.04-1.43]$ & $1.21[0.97-1.51]$ & \\
\hline Migration & & & $<0.0001$ \\
\hline Native French & $1[$ Ref $]$ & 1 [Ref] & \\
\hline Immigrant & $0.90[0.79-1.04]$ & $1.31[1.08-1.59]$ & \\
\hline Descendant of immigrant & $0.92[0.83-1.03]$ & $1.07[0.90-1.26]$ & \\
\hline Education level & & & $<0.0001$ \\
\hline$<$ Secondary school & $0.47[0.38-0.59]$ & $0.73[0.54-0.98]$ & \\
\hline Secondary school & $0.51[0.43-0.61]$ & $0.67[0.52-0.87]$ & \\
\hline High school & $0.68[0.60-0.79]$ & $0.74[0.59-0.93]$ & \\
\hline Two-year university degree & $0.76[0.68-0.86]$ & $0.89[0.73-1.09]$ & \\
\hline Three-year university degree & $0.89[0.79-1.00]$ & $0.90[0.74-1.11]$ & \\
\hline$\geq$ Five-year university degree & $1[$ Ref $]$ & $1[$ Ref $]$ & \\
\hline Employment status & & & $<0.0001$ \\
\hline Employed & 1 [Ref] & 1 [Ref] & \\
\hline Retired/disability/unemployed & $0.86[0.75-0.98]$ & $1.20[1.00-1.45]$ & \\
\hline Housewife/parental leave & $0.82[0.69-0.97]$ & $0.93[0.74-1.16]$ & \\
\hline Other & $0.84[0.62-1.14]$ & $0.64[0.38-1.07]$ & \\
\hline Student & $1.11[0.90-1.37]$ & $1.00[0.71-1.41]$ & \\
\hline Monthly family income & & & $<0.0001$ \\
\hline$<€ 1500$ & $0.62[0.51-0.75]$ & $0.89[0.69-1.14]$ & \\
\hline$€ 1501-2300$ & $0.77[0.68-0.89]$ & $1.06[0.87-1.28]$ & \\
\hline$€ 2301-3000$ & 1 [Ref] & 1 [Ref] & \\
\hline$€ 3001-4000$ & $1.05[0.94-1.16]$ & $1.03[0.87-1.22]$ & \\
\hline$€ 4001-5000$ & $1.10[0.95-1.26]$ & $0.98[0.77-1.23]$ & \\
\hline$>€ 5000$ & $1.32[1.13-1.54]$ & $0.91[0.69-1.19]$ & \\
\hline Pre-pregnancy body mass index & & & $<0.0001$ \\
\hline$<18.5 \mathrm{~kg} / \mathrm{m}^{2}$ & $1.06[0.91-1.23]$ & $1.31[1.05-1.63]$ & \\
\hline $18.5-24.9 \mathrm{~kg} / \mathrm{m}^{2}$ & 1 [Ref] & $1[$ Ref $]$ & \\
\hline $25.0-29.9 \mathrm{~kg} / \mathrm{m}^{2}$ & $0.79[0.71-0.88]$ & $0.93[0.79-1.10]$ & \\
\hline $30 \mathrm{~kg} / \mathrm{m}^{2}$ or more & $0.72[0.62-0.84]$ & $0.96[0.78-1.18]$ & \\
\hline Smoking status & & & $<0.0001$ \\
\hline Never smoked & 1 [Ref] & 1 [Ref] & \\
\hline Only before pregnancy & $1.10[1.01-1.21]$ & $1.04[0.89-1.21]$ & \\
\hline Only during early pregnancy & $0.72[0.58-0.88]$ & $1.09[0.82-1.47]$ & \\
\hline During the whole pregnancy & $0.68[0.60-0.77]$ & $0.89[0.74-1.07]$ & \\
\hline
\end{tabular}

Values are adjusted OR [95\% CI]. Multivariate multinomial logistic regression, also adjusted for maternal region of residence, size of maternity unit, and wave of recruitment. 
Women were more likely to start folic acid supplementation after the periconceptional period when they were older, underweight before pregnancy, or immigrant.

The results were very similar when the specific weighting to deal with non-inclusion bias was used in sensitivity analyses (Supplementary Table S2). Moreover, the results were not modified by excluding women with an unplanned pregnancy and those with fertility treatment. In the analysis by multiple imputation with five independent datasets, the findings were very consistent with those described in our main analysis.

\section{Discussion}

The results from our study revealed that only $26 \%$ of French pregnant women received folic acid supplementation during the periconceptional period. Moreover, we found that all dimensions related to the socioeconomic level (young maternal age, low education level, employment status, income, and single parenthood) were independently related to a lower odds ratio of pre-conceptional folic acid supplementation. These associations remained after excluding women with an unplanned pregnancy or those who had received fertility treatment.

In most countries in Europe, the rates of periconceptional supplementation are still low, even though guidelines on this public health issue were introduced more than 15 years ago. Most countries report folic acid supplementation rates of $25-35 \%$ during the periconceptional period [16]. In the Dutch Generation R cohort, 37\% of women received folic acid supplementation within the appropriate period [17]. The results were lower in Norway and Denmark, with $10 \%$ and $14 \%$ of women receiving folic acid supplementation during the periconceptional period, respectively [18,19]. In France, the results from the 2010 National Perinatal Survey indicated that $24 \%$ of women received folic acid supplementation in the periconceptional period [20], which is consistent with the rate highlighted in the present study. This low compliance with the folic acid supplementation guidelines could impair the effectiveness of the current neural tube defects prevention policy, and some studies have indicated that the implementation of the recommendations on folic acid supplementation is not clearly related to a decrease in the incidence of neural tube defects [21-23].

Folic acid supplementation rates vary according to country, but sociodemographic variables such as younger age of women and lower family income have consistently been associated with lower rates of folic acid supplementation $[17,18,24-26]$. European supplementation policies similar to those of France, without fortification policies, might, therefore, play a role in maintaining social inequalities $[27,28]$. In our study, social inequalities in periconceptional folic acid supplementation remained even when pregnancy planning was considered. This finding accentuates the poor preventive care during early pregnancy of the most socially disadvantaged women. The main reasons may be a decreased awareness in disadvantaged populations regarding this recommendation as well as their lower use of health care facilities [29,30]. To address this issue in the Netherlands, a mass media campaign was implemented in 1995 to increase the rate of folic acid supplementation [30].

Interestingly, in our study, women who stopped smoking before pregnancy were more likely to have folic acid supplementation during the periconceptional period, suggesting that they were probably more inclined to follow guidelines related to pregnancy and be involved in preventive care. This situation may give some leads for further folic acid supplementation strategies, such as considering the preventive prenatal care as a specific moment to address women's general health (nutrition, lifestyle, physical activity, smoking cessation).

Preventing neural tube defects by folic acid supplementation is a difficult goal to achieve, as changes in behavior are difficult to generate, and the human reproduction period can be long [31]. Indeed, the time between planning a pregnancy and becoming pregnant may take several months or even years, and women have first to achieve and maintain the objective of acid folic intake. To address this issue, more than 40 countries have decided to fortify foods with folic acid, and this strategy appears to be the most effective today $[8,23,29,32]$. This strategy could be particularly relevant for young and low-income women, because these groups of women are more likely to have unplanned 
pregnancies and less likely to receive or respond to health-promotion messages [16]. Studies in Canada suggest an improved efficacy of food fortification policies: while no effect on the incidence of neural tube defects was observed after recommendations of folic acid periconceptional supplementation between 1993 and 1997, a marked decrease in the incidence of neural tube defects was observed after food fortification implementation in $1997[8,23]$. The target group of this fortification policy are women of childbearing age, even though the general population has increased dietary folate intake [29]. This fortification strategy aims to supplement women continuously during their reproductive period, reaching women with unplanned pregnancies, and to limit social inequalities in health $[8,33]$. In 2017, a recommendation by the US Preventive Services Task Force (USPSTF) reinforced the importance of folic acid supplementation for all women of childbearing age (even in the absence of planned pregnancies) in addition to food fortification [34]. One of the disadvantages of this strategy concerns elderly people. Indeed, high folate intake may mask anemia resulting from vitamin B12 deficiency, which may cause neurological deterioration [35]. Moreover, there is a supposed relation between high intake of folic acid and cancer risk (especially colorectal cancer), even though human epidemiological data are inconclusive [36]. Even if voluntary fortification is very common in Europe (e.g., breakfast cereals, dairy products, fruit juices), mandatory food fortification is not practiced in any European countries mainly because of this cancer risk [36]. In France, systematic flour fortification with folic acid was considered. A pilot study to assess risks and benefits was proposed in early 2000s but ultimately was not launched. Our findings could contribute to this debate [37].

Some maternal characteristics, such as immigrant status and pre-pregnancy underweight status, were specifically related to folic acid supplementation only after the periconceptional period. This could be due to the fact that this late supplementation is not taken for the prevention of neural tube defects but is started following treatment for other pregnancy issues. The WHO recommends daily oral iron and folic acid supplementation among pregnant women to prevent maternal anaemia, puerperal sepsis, low birth weight, and preterm birth [38]. In the ELFE study, women who had started folic acid supplementation only after the periconceptional period were more likely to have haemoglobin levels below $11 \mathrm{~g} / 100 \mathrm{~mL}$ during pregnancy ( $15 \%$ vs $20 \%, p<0.0001)$, compared to women who received folic acid supplementation during the periconceptional period. Immigrant and underweight women are probably more at risk of maternal anaemia [39] and low birth weight.

The ELFE cohort is a representative study of births from the year 2011 in metropolitan France (excluding very premature babies), and descriptive statistics used weighted data to provide accurate prevalence of folic acid supplementation. In our multivariate analysis of the association between familial characteristics and folic acid supplementation, we excluded part of the sample because of missing data. The comparison of the characteristics of the women included versus those of the women excluded from the analysis showed that women with a higher educational level were overrepresented in the study, which may have implications for generalizing the findings. However, in sensitivity analyses based on multiple imputations of missing data, the results remained similar. Because women were recruited at delivery, it is necessary to acknowledge that miscarriages or medical abortions due to congenital malformations related to folic acid condition were not included in the present study. The main strengths of the ELFE study include the large sample size and the wide range of sociodemographic variables, which allowed us to demonstrate that various components of the social background were related to compliance with folic acid supplementation guidelines. Unfortunately, we were not able to distinguish between the timing patterns of folic acid supplementation related to neural tube defects prevention from supplementation for other purposes. Moreover, as we did not record the dose of folic acid consumed by women, we were not able to identify women with folic acid intake higher than the tolerable upper limit of $1000 \mu \mathrm{g} /$ day [40]. Finally, the study design did not allow to assess the effect of such supplementation on birth outcomes as stillbirth, very premature birth, and termination of pregnancy. 


\section{Conclusions}

Our study confirms low rates of folic acid supplementation during the periconceptional period as well as great social disparities concerning the use of maternal periconceptional folic acid supplementation. Therefore, it is important to find alternative methods, especially for vulnerable populations, to increase the effectiveness of prevention policies by considering media campaign.

Supplementary Materials: The following are available online at http://www.mdpi.com/2072-6643/11/5/1108/s1, Table S1: Type of variable, model used to predict missing data, and percentage of values missing for each variable included in the imputation model, Table S2: Sensitivity analyses on multivariate associations between familial characteristics and timing of folic acid supplementation in comparison to no supplementation

Author Contributions: The corresponding author affirms that all listed authors meet authorship criteria and that no others meeting these criteria have been omitted. A.C. conceptualized and designed the study, conducted the statistical analyses, interpreted the results, drafted the initial manuscript, and approved the final manuscript as submitted. M.K., S.L., C.B., M.C. and M.-N.D. critically reviewed the manuscript and approved the final version submitted. M.A.C. and B.d.L.-G. conceptualized and designed the study, contributed to the interpretation of the results, reviewed and revised the manuscript, and approved the final manuscript as submitted. A.C. and B.d.L.-G. are sponsors of the present work.

Funding: This analysis was funded by an ANR grant within the framework "Social determinants of health" (grant number: ANR-12-DSSA-0001). The Elfe survey is a joint project between the French Institute for Demographic Studies (INED) and the National Institute of Health and Medical Research (INSERM), in partnership with the French blood transfusion service (Etablissement français du sang, EFS), Santé publique France, the National Institute for Statistics and Economic Studies (INSEE), the Direction générale de la santé (DGS, part of the Ministry of Health and Social Affairs), the Direction générale de la prévention des risques (DGPR, Ministry for the Environment), the Direction de la recherche, des études, de l'évaluation et des statistiques (DREES, Ministry of Health and Social Affairs), the Département des études, de la prospective et des statistiques (DEPS, Ministry of Culture), and the Caisse nationale des allocations familiales (CNAF), with the support of the Ministry of Higher Education and Research and the Institut national de la jeunesse et de l'éducation populaire (INJEP). Via the RECONAI platform, it receives a government grant managed by the National Research Agency under the "Investissements d'avenir" programme (ANR-11-EQPX-0038).

Acknowledgments: We would like to thank the scientific coordinators (Marie Aline Charles, Bertrand Geay, Henri Léridon, Corinne Bois, Marie-Noëlle Dufourg, Jean-Louis Lanoé, Xavier Thierry, Cécile Zaros), IT and data managers, statisticians (A Rakotonirina, R Kugel, R Borges-Panhino, M Cheminat, H Juillard), administrative and family communication staff, and study technicians (C Guevel, M Zoubiri, L Gravier, I Milan, R Popa) of the ELFE coordination team as well as the families who gave their time for the study.

Conflicts of Interest: The authors have no conflicts of interest relevant to this study to disclose. The authors have no financial relationship relevant to this study to disclose.

\section{References}

1. Eurocat. Cases and Prevalence (Per 10,000 Births) for All Full Member Registries from 2010 to 2014. Available online: http://www.eurocat-network.eu/ACCESSPREVALENCEDATA/PrevalenceTables (accessed on 21 February 2017).

2. Santé Publique France. Malformations Congénitales Et Anomalies Chromosomiques; Santé Publique France: Saint-Maurice, France, 2014.

3. De-Regil, L.M.; Pena-Rosas, J.P.; Fernandez-Gaxiola, A.C.; Rayco-Solon, P. Effects and safety of periconceptional oral folate supplementation for preventing birth defects. Cochrane Database Syst. Rev. 2015. [CrossRef] [PubMed]

4. MRC Vitamin Study Research Group. Prevention of neural tube defects: Results of the Medical Research Council Vitamin Study. Lancet 1991, 338, 131-137. [CrossRef]

5. Czeizel, A.E.; Dudas, I. Prevention of the first occurrence of neural-tube defects by periconceptional vitamin supplementation. N. Engl. J. Med. 1992, 327, 1832-1835. [CrossRef]

6. Cawley, S.; Mullaney, L.; McKeating, A.; Farren, M.; McCartney, D.; Turner, M.J. A review of European guidelines on periconceptional folic acid supplementation. Eur. J. Clin. Nutr. 2016, 70, 143-154. [CrossRef] [PubMed]

7. Bentley, T.G.K.; Willett, W.C.; Weinstein, M.C.; Kuntz, K.M. Population-Level Changes in Folate Intake by Age, Gender, and Race/Ethnicity after Folic Acid Fortification. Am. J. Public Health 2006, 96, 2040-2047. [CrossRef] [PubMed] 
8. Mills, J.L. Strategies for Preventing Folate-Related Neural Tube Defects: Supplements, Fortified Foods, or Both? JAMA 2017, 317, 144-145. [CrossRef]

9. Avis de l'ANSES Relatif à l'Actualisation des Repères du PNNS: Révision des Références Nutritionnelles en Vitamines et Minéraux Pour la Population Générale Adulte; French Agency for Food Environmental and Occupational Health \& Safety: Maisons-Alfort, France, 2016.

10. Sedgh, G.; Singh, S.; Hussain, R. Intended and unintended pregnancies worldwide in 2012 and recent trends. Stud. Fam. Plan. 2014, 45, 301-314. [CrossRef]

11. Guthmann, J.-P.; Célant, N.; Parent du Chatelet, I.; Duport, N.; Levy-Bruhl, D.; Rochereau, T.; Celant, N.; InVS; IRDES. Déterminants socio-économiques de vaccination et de dépistage du cancer du col par frottis cervico-utérin (FCU). In Analyse de l'enquête santé et Protection Sociale (ESPS), 2012; Institut de Veille Sanitaire: Saint-Maurice, France, 2016.

12. Sambamoorthi, U.; McAlpine, D.D. Racial, ethnic, socioeconomic, and access disparities in the use of preventive services among women. Prev. Med. 2003, 37, 475-484. [CrossRef]

13. Lorant, V.; Boland, B.; Humblet, P.; Deliege, D. Equity in prevention and health care. J. Epidemiol. Community Health 2002, 56, 510-516. [CrossRef]

14. Vandentorren, S.; Bois, C.; Pirus, C.; Sarter, H.; Salines, G.; Leridon, H.; Elfe Team. Rationales, design and recruitment for the Elfe longitudinal study. BMC Pediatr. 2009, 9, 58. [CrossRef] [PubMed]

15. Blondel, B.; Lelong, N.; Kermarrec, M.; Goffinet, F.; The National Coordination Group of the National Perinatal Surveys. Trends in perinatal health in France from 1995 to 2010. Results from the French National Perinatal Surveys. J. Gynecol. Obstet. Biol. Reprod. 2012, 41, e1-e15. [CrossRef] [PubMed]

16. Stockley, L.; Lund, V. Use of folic acid supplements, particularly by low-income and young women: A series of systematic reviews to inform public health policy in the UK. Public Health Nutr. 2008, 11, 807-821. [CrossRef] [PubMed]

17. Timmermans, S.; Jaddoe, V.W.; Mackenbach, J.P.; Hofman, A.; Steegers-Theunissen, R.P.; Steegers, E.A. Determinants of folic acid use in early pregnancy in a multi-ethnic urban population in The Netherlands: The Generation R study. Prev. Med. 2008, 47, 427-432. [CrossRef]

18. Nilsen, R.M.; Vollset, S.E.; Gjessing, H.K.; Magnus, P.; Meltzer, H.M.; Haugen, M.; Ueland, P.M. Patterns and predictors of folic acid supplement use among pregnant women: The Norwegian Mother and Child Cohort Study. Am. J. Clin. Nutr. 2006, 84, 1134-1141. [CrossRef] [PubMed]

19. Knudsen, V.K.; Orozova-Bekkevold, I.; Rasmussen, L.B.; Mikkelsen, T.B.; Michaelsen, K.F.; Olsen, S.F. Low compliance with recommendations on folic acid use in relation to pregnancy: Is there a need for fortification? Public Health Nutr. 2004, 7, 843-850. [CrossRef] [PubMed]

20. Blondel, B.; Kermarrec, M. Les Naissances En 2010 Et Leur Evolution Depuis 2003; Inserm-U 953: Paris, France, 2011.

21. Botto, L.D.; Lisi, A.; Robert-Gnansia, E.; Erickson, J.D.; Vollset, S.E.; Mastroiacovo, P.; Botting, B.; Cocchi, G.; de Vigan, C.; de Walle, H.; et al. International retrospective cohort study of neural tube defects in relation to folic acid recommendations: Are the recommendations working? BMJ 2005, 330, 571. [CrossRef] [PubMed]

22. De Walle, H.; Abramsky, L. Prevention of Neural Tube Defects by Periconceptional Folic Acid Supplementation in Europe; Eurocat: Newtownabbey, UK, 2009.

23. De Wals, P.; Tairou, F.; Van Allen, M.I.; Uh, S.H.; Lowry, R.B.; Sibbald, B.; Evans, J.A.; Van den Hof, M.C.; Zimmer, P.; Crowley, M.; et al. Reduction in neural-tube defects after folic acid fortification in Canada. N. Engl. J. Med. 2007, 357, 135-142. [CrossRef]

24. McGuire, M.; Cleary, B.; Sahm, L.; Murphy, D.J. Prevalence and predictors of periconceptional folic acid uptake-prospective cohort study in an Irish urban obstetric population. Hum. Reprod. 2010, 25, 535-543. [CrossRef] [PubMed]

25. Tort, J.; Lelong, N.; Prunet, C.; Khoshnood, B.; Blondel, B. Maternal and health care determinants of preconceptional use of folic acid supplementation in France: Results from the 2010 National Perinatal Survey. BJOG 2013, 120, 1661-1667. [CrossRef]

26. Ami, N.; Bernstein, M.; Boucher, F.; Rieder, M.; Parker, L.; Canadian Paediatric Society, D.T.; Hazardous Substances, C. Folate and neural tube defects: The role of supplements and food fortification. Paediatr. Child Health 2016, 21, 145-154. [CrossRef] [PubMed] 
27. Mallard, S.R.; Gray, A.R.; Houghton, L.A. Delaying mandatory folic acid fortification policy perpetuates health inequalities: Results from a retrospective study of postpartum New Zealand women. Hum. Reprod. 2012, 27, 273-282. [CrossRef] [PubMed]

28. de Walle, H.E.; Cornel, M.C.; de Jong-van den Berg, L.T. Three years after the dutch folic acid campaign: Growing socioeconomic differences. Prev. Med. 2002, 35, 65-69. [CrossRef] [PubMed]

29. Eichholzer, M.; Tonz, O.; Zimmermann, R. Folic acid: A public-health challenge. Lancet 2006, 367, $1352-1361$. [CrossRef]

30. de Walle, H.E.; de Jong-van den Berg, L.T. Ten years after the Dutch public health campaign on folic acid: The continuing challenge. Eur. J. Clin. Pharmacol. 2008, 64, 539-543. [CrossRef] [PubMed]

31. Mitchell, L.E. Folic Acid for the Prevention of Neural Tube Defects: The US Preventive Services Task Force Statement on Folic Acid Supplementation in the Era of Mandatory Folic Acid Fortification. JAMA Pediatr. 2017, 171, 217-218. [CrossRef] [PubMed]

32. Willet, W.C. Nutritional Epidemiology; Oxford University Press: New York, NY, USA, 2012.

33. Meijer, W.M.; de Walle, H.E. Differences in folic-acid policy and the prevalence of neural-tube defects in Europe; recommendations for food fortification in a EUROCAT report. Ned. Tijdschr. Geneeskd. 2005, 149, 2561-2564. [PubMed]

34. Jin, J. Folic Acid Supplementation for Prevention of Neural Tube Defects. JAMA 2017, 317, 222. [CrossRef]

35. De Benoist, B. Conclusions of a WHO Technical Consultation on folate and vitamin B12 deficiencies. Food Nutr. Bull. 2008, 29, S238-S244. [CrossRef] [PubMed]

36. Reilly, A.; Amberg-Mueller, J.; Beer, M.; Busk, L.; Castellazzi, A.-M.; Castenmiller, J.; Flynn, M.; Margaritis, I.; Lampen, A.; Parvan, C.; et al. ESCO Report on Analysis of Risks and Benefits of Fortification of Food with Folic Acid; EFSA European Food Safety Authority: Parma, Italy, 2009.

37. Czernichow, S.; Blacher, J.; Ducimetière, P. Enrichissement de la Farine en Vitamines B en France Proposition d'un Programme-Pilote; AFSSA: Maison Alfort, France, 2003.

38. World Health Organization. WHO Recommendations on Antenatal Care for a Positive Pregnancy Experience; World Health Organization: Geneva, Switzerland, 2016.

39. Arnaud, A.; Lioret, S.; Vandentorren, S.; Le Strat, Y. Anaemia and associated factors in homeless children in the Paris region: The ENFAMS survey. Eur. J. Public Health 2017. [CrossRef]

40. Navarrete-Munoz, E.M.; Valera-Gran, D.; Garcia de la Hera, M.; Gimenez-Monzo, D.; Morales, E.; Julvez, J.; Riano, I.; Tardon, A.; Ibarluzea, J.; Santa-Marina, L.; et al. Use of high doses of folic acid supplements in pregnant women in Spain: An INMA cohort study. BMJ Open 2015, 5, e009202. [CrossRef] 